\title{
Uzaktan Eğitimle Türkçe Öğrenme Sürecinde A1 düzeyindeki Arap Öğrencilerin Karşılaştıkları Güçlükler ve Çözüm Önerileri
}

\section{A1 Level Arab Students' Encountered Difficulties and Suggestions for Solutions in the Process of Learning Turkish with Distance Education}

https://doi.org/10.52105/temelegitim.12.2

\author{
Mustafa BAŞARAN ${ }^{1}$
}

https://orcid.org/0000-0003-1684-5852

Rania BENSEGHIR ${ }^{2}$

https://orcid.org/0000-0003-1684-5852

Geliş Tarihi/Received: 25/04/2021 Kabul Tarihi/Accepted: 28/08/2021 Yayın Tarihi/Published: 15/10/2021

\begin{abstract}
Özet:
Arap öğrencilerin COViT-19 salgını sürecinde uzaktan eğitimle Türkçe öğrenimi sürecinde karşılaştıkları güçlükleri ve önerdikleri çözümleri tespit etmek amacıyla yapılan bu araştırmada nicel araştırma yaklaşımı ve alan araştırma yöntemlerinden tarama kullanılmıştır. Araştırmanın örneklemini Arap ülkelerinde yaşayan ve yabancı dil olarak Türkçe öğrenen A1 düzeyindeki 100 öğrenci oluşturmaktadır. Araştırma sonucunda öğrencilerin en sık karşılaştıkları sorunlar, "uzaktan eğitimle ders işlerken yaşanan bağlantı problemleri", "yayın kalitesinin düşüklüğü", "evdeki fiziki imkanların sınırlı olması", "saat farkı dolayısıyla ortaya çıkan problemler", "ödevleri yalnız yapmanın zorluğu" ve "ekran karşısında uzun süre kalma" olarak sıralanabilir. Öğrencilerin önerdiği çözüm önerileri ise "uzaktan eğitim için günlük ders çalışma planı hazırlanması", "pandemide egzersizler yaparak moral ve sağlığın korunması", "Türkçe kitap okunması", "derslerin tekrarının izlenmesi", "ekran karşısında geçirilen zaman dikkat edilmesi", "eğitsel oyunların oynanması", "Türkçe film belgesel veya animasyonların izlenmesi", "ders sorumlusuyla ders dışında da iletişime devam edilmesi" ve "sanal olarak Türkiye'de bulunan müze, sinema, tiyatroların gezilmesi" şeklindedir.

Anahtar kelimeler: Yabancı dil olarak Türkçe öğretimi, Araplara Türkçe öğretimi, Uzaktan eğitim
\end{abstract}

\begin{abstract}
:
The method of this research, which was carried out in order to determine the difficulties encountered by Arab students in the process of learning Turkish through distance education during the pandemic process and the solution proposals they offer, is relational screening, one of the quantitative research methods. The sample of the research consists of 100 students at A1 level living in Arab countries and learning Turkish as a foreign language. As a result of the research, the most common problems faced by the students are "Connection problems while teaching with distance education", "poor broadcast quality", "limited physical facilities at home", "sleep due to time difference, etc. problems", "difficulty doing homework" and "staying in front of the screen for a long time". The solution suggestions offered by the students are "daily study plan should be prepared for distance education", "morale and health should be protected by doing exercises in the pandemic", "it is necessary to read books in Turkish", "the repetition of the lessons should be watched", "the time spent in front of the screen should be paid attention", plays should be played", "Turkish films, documentaries or animations should be watched", and "must see museums, cinemas and theaters in Turkey virtually".
\end{abstract}

Key words: Teaching Turkish as a foreign language, Teaching Turkish to Arabs, Distance education.

Önerilen Atıf Bilgisi/To Cite This Article: Başaran, M., ve Benseghir, R. (2021). Uzaktan Eğitimle Türkçe Öğrenme Sürecinde A1 düzeyindeki Arap Öğrencilerin Karşılaştıkları Güçlükler ve Çözüm Önerileri, Temel Eğitim Dergisi, 12, 18-24. https://doi.org/10.52105/temelegitim.12.2

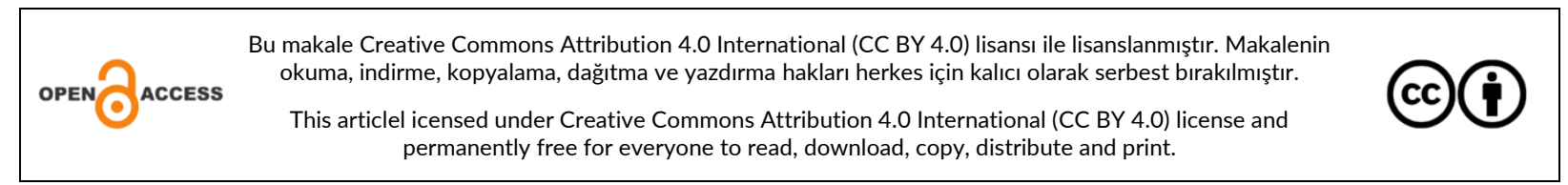

\footnotetext{
${ }^{1}$ Yıldız Teknik Üniversitesi, Eğitim Fakültesi, mbasaran66@yahoo.com

${ }^{2}$ raniabenseghir@gmail.com
} 


\section{Giriş}

Günümüzde yabancı bir dil öğrenmenin önemi oldukça artmıştır. Bu sebepten bireyler özellikle mesleki ve kişisel gelişimlerine katkı sağlamak için yabancı bir dil öğrenmek için türlü fırsatlar aramaktadır. Uzaktan eğitimin sağladığı fırsatlar ise bir hayli fazladır. Özellikle COViD-19 salgını ile birlikte başlangıçta palyatif bir çözüm olarak kullanılan uzaktan eğitimin ne kadar fazla öğrenme fırsatı ve kolaylığı sağladığı anlaşılmıştır. Halihazırda yüz yüze eğitimin mümkün olmağı durumlarda veya karantina şartlarında kullanılan birçok uzaktan eğitim uygulaması, eğitim yöneticileri, öğretmenler ve öğrencilerin güvenini kazanmış durumdadır.

Birçok resmi ve özel kurum tarafından yapıldığı ve çok sayıda kişinin yabancı dil olarak Türkçe öğrendiği göz önüne alındığında bu alanda son yıllarda önemli ve çok sayıda gelişme yaşandığı söylenebilir. Gerçekten de Türkçe, çok geniş bir coğrafyada milyonlarca insanın konuştuğu kökeni çok eskilere dayalı bir dildir (Barın, 2004; Ağar, 2004; Biçer, 2012). Bu sebeple tarihi çok eskilere dayanan Türkçe yazılmış çok sayıda eser bulunmaktadır. Günümüzde de pek çok alanda, çok sayıda Türkçe eser yazılmaya devam etmektedir. Ayrıca dünyanın birçok ülkesindeki üniversitelerde Türkçe öğretilmekte ve Türkçe üzerine bilimsel çalışmalar yapılmaktadır. Gerek Türkiye'nin güttüğü uluslararası politikalar gerek dünyada meydana gelen sosyo-politik değişimler gerekse de Türkiye'nin sınırlarında meydana gelen siyasi-askeri olaylar sonucu son yıllarda yabancı dil olarak Türkçeyi öğrenenlerin sayısını katlanarak arttırmıştır (Alyılmaz, 2010; Barın, 2003; Durmuş, 2013; Er vd., 2012; Göçer vd., 2011; Güler, 2012; Gün vd., 2014; Karababa, 2009; Özdemir, 2013). Salgın sürecinde de uzaktan eğitimle yabancı dil olarak Türkçe öğretimi hususunda önemli tecrübeler kazanılmıştır. Ancak günümüzde Türkçenin yabancı dil olarak öğretiminde uzun yıllardan beri elde edilen tecrübe ve Türkiye Cumhuriyeti Devletinin gayretlerine rağmen hâlen bazı problemlerle karşılaşılmaktadır. Bu problemlerden en önemlileri; yabancılara Türkçe öğretimi alanında yetişmiş nitelikli öğretmen sayısının azlığı, Türkçe öğretimi programının yabancı öğrencilerin ana dilinin yapısına, eğitim düzeyine ve kültürüne göre hazırlanmaması, Türk dilinin yapısal özelliklerinden kaynaklanan problemler ve Türkçe öğretiminde kullanılan yöntem, teknik ve materyaller ihtiyaca cevap vermemesi şekilde sıralanabilir (Durmuş, 2013; Göçer vd., 2011; Güler, 2012; Karababa, 2009; Özdemir, 2013;). Uzaktan eğitimin kendine has fırsatları olduğu gibi çeşitli zorlukları da bulunduğundan, yabancı dil olarak Türkçenin öğretiminde karşılaşılan bu problemlerin, etkili ve kalıcı öğrenmeyi engelleyici etkileri söz konusu olabilir.

Yeni Tip Korona Virüs (2019-nCoV), 2019 yılının sonlarında Çin Halk Cumhuriyeti'nde ortaya çıkmış ve bütün dünyaya yayılmıştır. 2020 yılının Mart ayında ise Dünya Sağlık Örgütü (DSÖ) pandemi ilan edilmiştir. Salgına karşı alınan tedbirlerden biri de okulların tatil edilmesi olmuştur. Tüm dünyada olduğu gibi Türkiye'de de Millî Eğitim Bakanlığı (MEB) 23 Mart 2020 tarihi itibariyle bütün kademelerdeki okulları yüz yüze eğitime kapatarak uzaktan eğitime geçmiştir. Covid-19 pandemisi hızlı ve öngörülemez şekilde başladığından, pek çok kurum çeşitli zorluklar yaşamıştır. Eğitim kurumları da bunların başında gelmektedir. Çünkü çocuklar okullarda eğitim görmekte iken bir anda kendilerini evlerinin odalarında bilgisayar veya TV ekranları karşısında ders dinlerken bulmuşlardır. Ancak yukarıda da değinildiği gibi uzaktan eğitime birden geçilmesi bazı zorluklara neden olmakla birlikte pek çok fırsatı da beraberinde getirmiştir. Dijital çağda doğmuş çocuklar için zorunlu şekilde kullanılan uzaktan eğitim, öğretmen ve ailelerin de zorunlu olarak dijital araçları sıklıkla kullanmalarına sebep olmuş ve yeni becerilerin kazanılmasına neden olmuştur.

Uzaktan eğitim, her ne kadar kazanımlar açısından farklııı arz etmese de, süreçte kullanılan araç gereçler, öğretim sürecinin planlanması, öğrencilerin derslere katıldığı fiziki ortamlar ve sınıf içi etkileşim vb. açılardan değerlendirildiğinde yüz yüze eğitimden oldukça farklıdır. Uzaktan eğitimde karşılaşılan problemlerin kaynağı daha çok öğrencinin kullandığı elektronik cihazların niteliği, kullanılan internet alt yapısı, ailenin süreçte öğrenciye sağladığı eğitsel ve sosyal desteğin yanında evdeki fiziki ortamı düzenlemesi ve öğretmenlerin uzaktan eğitime adaptasyonuna bağlı olduğu söylenebilir (Bakioğlu ve Çevik, 2020; Bozkurt, 2020; Dikmen, ve Bahçeci, 2020; Durak, Çankaya ve İzmirli, 2020; Keskin ve Özer Kaya, 2020; Sancak ve Çöl, 2020; Serçemeli ve Kurnaz,2020).

\section{Araştırmanın amacı}

Bu çalışmanın temel amacı kendi ülkelerinde yaşayan ve pandemi sürecinde Türkçe öğrenmeye başlayan A1 düzeyindeki Arap öğrencilerin, uzaktan eğitimle Türkçe öğrenirken karşılaştıkları güçlükleri ve çözüm önerilerini tespit etmektir. 


\section{Yöntem}

A1 düzeyindeki Arap öğrencilerin, uzaktan eğitimle Türkçe öğrenirken karşılaştıkları güçlükleri ve çözüm önerilerini tespit etmek amacıyla yapılan bu çalışmada nicel araştırma yaklaşımı ve alan araştırma yöntemlerinden tarama modeli; veri toplama tekniği olarak da çevrimiçi anket kullanılmıştır. Tarama, nicel araştırma yöntemlerinden tarama desenleri arasında yer almaktadır. Bu desende alandaki mevcut durum dışarıdan müdahale olmadan incelenmektedir (Büyüköztürk vd., 2008; Creswell, 2011).

\section{Evren ve Örneklem}

Bu araştırmanın çalışma evreni uzaktan eğitimle yabancı dil olarak Türkçe öğrenen A1 düzeyindeki Arap öğrencilerdir. Bu evrenden amaçlı örnekleme yöntemlerinden kriter örnekleme tekniği kullanılarak seçilen 100 öğrenci ise araştırmanın örneklemini oluşturmaktadır. Örnekleme seçilen öğrencilerin,

- Türkçe bilgilerinin A1 düzeyinde olmasına

- Anadilinin Arapça olmasına

- Uzaktan eğitimle Türkçe öğrenmelerine

- Türkçe öğrenirken Yunus Emre Enstitüsünün ders kitaplarını kullanmalarına dikkat edilmiştir.

Örnekleme alınan 100 öğrencinin 15'i erkek; (\%15) 85'i (\%85) ise kadındır. 36 öğrenci (\%36) 15-20 yaş; 64'ü ise (\%64) 20-30 yaş aralığındadır. Katılımcıların 68'i lisans lisans aşamasındadır. 32 öğrenci ise lise eğitimine devam etmektedir.

\section{Ölçme Aracı}

Araştırmada araştırmacılar tarafından geliştirilen anket kullanılmıştır. Anket Arapça olarak uygulanmıştır. Ankette katılımcıların uzaktan öğrenme ortamlarında yabancı dil olarak Türkçe öğrenirken karşılaştıkları problemler ve çözüm önerilerine ilişkin maddeler bulunmaktadır. Anket beşli likert şeklinde hazırlanmıştır. Anketin geçerliliği Türkçe öğretimi alanında doktorasını tamamlamış beş alan uzmanının görüşü alınarak sağlanmıştır. Ölçeğin güvenilirliği için test tekrar test yöntemi kullanılmıştır. Bu uygulama için anadili Arapça olan, yabancı dil olarak Türkçe öğrenen ve en az B1 düzeyinde olan 30 öğrenciye anket iki hafta arayla tekrar uygulanmıştır. Bu uygulama sonrasında her bir anket maddesi için her iki uygulama arasındaki korelasyona ayrı ayrı bakılmış ve iki uygulama arasındaki korelasyonun her madde için en az .92 düzeyinde olduğu görülmüştür.

\section{Uygulama}

Çalışma iki araştırmacı tarafından yürütülmüştür. Araştırmacılardan birinin anadili Arapçadır ve C2 düzeyinde Türkçe bilgisine sahiptir. Diğer araştırmacı ise Türkçenin öğretimi alnında doktorasını tamamlamıştır. Araştırmada öncelikle anadili Arapça olan ve Türkçe öğrenmek isteyen A1 düzeyindeki öğrencilere ulaşılmış ve bu öğrencilere Yunus Emre Enstitüsü'nün yabancı dil olarak Türkçe öğretimi amacıyla hazırladığı ders materyalleri kullanılarak üç ay boyunca haftada üç gün altı saat olmak üzere canlı ders anlatımı ile Türkçe öğretimi yapılmıştır. Bu derslerde öğretmen ve öğrencilerin canlı olarak yazılı ve sözlü iletişim kurmasına imkan veren uygulamalar kullanılmıştır. Bu sürecin sonunda öğrencilerin gönüllülük esasına dayalı olarak sürece ilişkin karşılaştıkları güçlükleri ve çözüm önerilerini belirlemeye yönelik olarak araştırmacılar tarafından hazırlanan anket çevrimiçi olarak uygulanmıştır. Bu uygulamadan önce dileyen öğrencilerin araştırmadan istedikleri anda ayrılabileceği söylenmiş ve bunun için ilgili link çevrimiçi anketin sonuna eklenmiştir. Hiçbir katılımcı araştırmadan ayrılmamıştır.

\section{Bulgular}

Tablo 1. Öğrencilerin Türkçe öğrenmenin zorluğuna ilişkin görüşleri

\begin{tabular}{lll}
\hline & $\mathbf{F}$ & $\mathbf{\%}$ \\
\hline Çok zor & 6 & $6 \%$ \\
\hline Zor & 18 & $18 \%$ \\
\hline Orta zorlukta & 53 & $53 \%$ \\
\hline Kolay & 19 & $19 \%$ \\
\hline Çok kolay & 4 & $4 \%$ \\
\hline
\end{tabular}


Tablo 1 incelendiğinde öğrencilerin yarısından fazlasının (\%53) Türkçe öğrenmenin orta zorlukla; 24'ünün (\%24) ise zor veya çok zor olduğunu düşündüğü görülmektedir. Türkçe öğrenmeyi kolay ve çok kolay bulanların sayısı ise 23'tür (\%23). Bu sonuçlardan hareketle Arap öğrenciler için Türkçe öğrenmenin zor olduğu söylenebilir.

Tablo 2. Yabancı Dil Olarak Türkçe Öğrenen Arap Öğrencilerin Uzaktan Öğretim Sürecinde Karşılaştıkları Güçlükler

\begin{tabular}{|c|c|c|c|c|c|c|c|c|c|c|}
\hline \multirow[t]{2}{*}{ Problemler } & \multicolumn{2}{|c|}{ 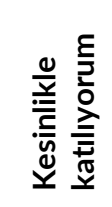 } & \multicolumn{2}{|c|}{ 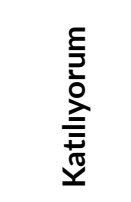 } & \multicolumn{2}{|c|}{ 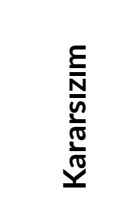 } & \multicolumn{2}{|c|}{ 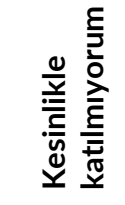 } & \multicolumn{2}{|c|}{ 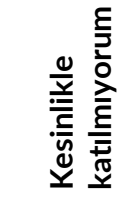 } \\
\hline & $\mathrm{F}$ & $\%$ & $\mathrm{~F}$ & $\%$ & $\mathrm{~F}$ & $\%$ & $\mathrm{~F}$ & $\%$ & $\mathrm{~F}$ & $\%$ \\
\hline Ders işlerken bağlantım kesiliyor & 7 & 7 & 54 & 54 & 5 & 5 & 22 & 22 & 12 & 12 \\
\hline Ders işlerken yayın donuyor & 6 & 6 & 35 & 35 & 8 & 8 & 41 & 41 & 10 & 10 \\
\hline Teknolojik araçları kullanmayı bilmiyorum. & 1 & 1 & 15 & 15 & 6 & 6 & 39 & 39 & 39 & 39 \\
\hline Teknoloji kullanma konusunda bana yardımcı olacak kimsem yok & 2 & 2 & 14 & 14 & 6 & 6 & 42 & 42 & 36 & 36 \\
\hline Uzaktan eğitimde ders dinleyeceğim ortam uygun olmuyor & 2 & 2 & 19 & 19 & 10 & 10 & 34 & 34 & 35 & 35 \\
\hline $\begin{array}{l}\text { Evde uzaktan eğitim alan kardeşimin/ kardeşlerimin olması sorunlarına } \\
\text { yol açıyor }\end{array}$ & 4 & 4 & 20 & 20 & 7 & 7 & 42 & 42 & 27 & 27 \\
\hline $\begin{array}{l}\text { Uzaktan eğitim sürecinde ders saatleriyle ile uyku düzenim arasında } \\
\text { uyumsuzluk var }\end{array}$ & 3 & 3 & 18 & 18 & 7 & 7 & 47 & 47 & 25 & 25 \\
\hline Uzaktan eğitim sürecinde ödevleri yalnız yapmak zor oluyor & 4 & 4 & 28 & 28 & 8 & 8 & 42 & 42 & 18 & 18 \\
\hline Ekran karşısında uzun süre zaman geçirmekte zorlanıyorum & 8 & 8 & 26 & 26 & 9 & 9 & 37 & 37 & 20 & 20 \\
\hline Dersi daha etkili dinlemek için gerekli (mikrofon vb. ) araçlarım yok & 3 & 3 & 17 & 17 & 5 & 5 & 45 & 45 & 30 & 30 \\
\hline Sınıf arkadaşlarımın uyumsuz davranışları dersin verimliliğini düşürüyor & 8 & 8 & 19 & 19 & 6 & 6 & 36 & 36 & 31 & 31 \\
\hline
\end{tabular}

Tablo 3 incelendiğinde öğrencilerin uzaktan eğitimde yabancı dil olarak Türkçe öğrenme sürecinde sırasıyla "Uzaktan eğitimle ders işlerken yaşanan bağlantı problemleri", "yayın kalitesinin düşüklüğü", "evdeki fiziki imkanların sınılı olması", "saat farkı dolayısıyla ortaya çıkan problemler", "ödevleri yalnız yapmanın zorluğu" ve "ekran karşısında uzun süre kalma" problemleri yaşadığı söylenebilir.

Tablo 4. Uzaktan Eğitimle Yabancı Dil Olarak Türkçe Öğrenme Sürecini Daha Etkili Hale Getirebilmek İçin Sunulan Çözüm Önerilerine Öğrencilerin Katılım Durumları

\begin{tabular}{|c|c|c|c|c|c|c|c|c|c|c|}
\hline \multirow[t]{2}{*}{ Çözüm önerileri } & \multicolumn{2}{|c|}{ 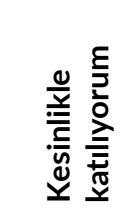 } & \multicolumn{2}{|c|}{ 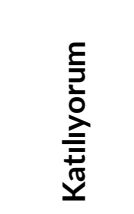 } & \multicolumn{2}{|c|}{ 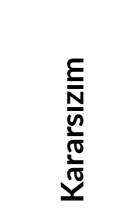 } & \multicolumn{2}{|c|}{ 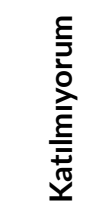 } & \multicolumn{2}{|c|}{ 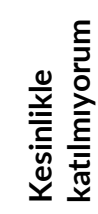 } \\
\hline & $\mathbf{F}$ & $\%$ & $\mathbf{F}$ & $\%$ & $\mathbf{F}$ & $\%$ & $\mathbf{F}$ & $\%$ & $\mathbf{F}$ & $\%$ \\
\hline Öğretmen ile ders dışında da iletişimi devam ettirmek gerekir. & 48 & 48 & 40 & 40 & 5 & 5 & 1 & 1 & 6 & 6 \\
\hline Diğer Türkçe öğretmenleri ile de iletişim kurmak gerekir. & 29 & 29 & 32 & 32 & 29 & 29 & 5 & 5 & 5 & 5 \\
\hline Türkçe öğrenen diğer öğrencilerle iletişim kurmak gerekir. & 35 & 35 & 42 & 42 & 19 & 19 & 1 & 1 & 3 & 3 \\
\hline Aile desteği sağlanmalı. & 43 & 43 & 34 & 34 & 18 & 18 & 2 & 2 & 3 & 3 \\
\hline Günlük ders çalışma planı hazırlanmalıdır. & 43 & 43 & 39 & 39 & 13 & 13 & 3 & 3 & 2 & 2 \\
\hline Fiziksel egzersizler yaparak moral ve sağlık korunmalıdır. & 50 & 50 & 41 & 41 & 5 & 5 & 2 & 2 & 2 & 2 \\
\hline Türkçe kitap okumak gerekir. & 46 & 46 & 36 & 36 & 14 & 14 & 2 & 2 & 2 & 2 \\
\hline Derslerin tekrarı izlenmelidir. & 45 & 45 & 37 & 37 & 13 & 13 & 0 & 0 & 3 & 3 \\
\hline Ekran karşısında geçirilen zaman dikkat edilmelidir. & 43 & 43 & 39 & 39 & 12 & 12 & 3 & 3 & 3 & 3 \\
\hline Eğitsel oyunlar oynanmalıdır. & 46 & 46 & 40 & 40 & 4 & 4 & 1 & 1 & 1 & 1 \\
\hline
\end{tabular}


Temel Eğitim Dergisi / Journal of Primary Education, 2021, 12, 18-24

\begin{tabular}{|c|c|c|c|c|c|c|c|c|c|c|}
\hline Türkçe film belgesel veya animasyon izlenmelidir. & 50 & 50 & 38 & 38 & 9 & 9 & 1 & 1 & 2 & 2 \\
\hline $\begin{array}{l}\text { Sanal ortamlarda Türkiye'de bulunan müze, sinema, tiyatro } \\
\text { gezmek gerekir. }\end{array}$ & 42 & 42 & 38 & 38 & 9 & 9 & 1 & 1 & 2 & 2 \\
\hline $\begin{array}{l}\text { Online dersi dinledikten sonra derste işlenen konuyu başka } \\
\text { kaynaklardan da tekrar edilmelidir. }\end{array}$ & 39 & 39 & 35 & 35 & 17 & 17 & 1 & 1 & 2 & 2 \\
\hline $\begin{array}{l}\text { Dersleri sunan kurumlar teknolojik cihazların ve uygulamaların } \\
\text { nasıl kullanılacağını da öğretilmelidir. }\end{array}$ & 39 & 39 & 42 & 42 & 12 & 12 & 3 & 3 & 4 & 4 \\
\hline
\end{tabular}

Tablo incelendiğinde öğrencilerin uzaktan eğitimle Türkçe öğretimi sürecinin daha etkili olması için önerdikleri çözümler şu şekilde sıralanabilir: Fiziksel egzersizler yaparak moral ve sağlık korunmalı; öğretmen ile ders dışında da iletişimi devam ettirilmeli; Türkçe kitap okunmalı; Türkçe film belgesel veya animasyonlar izlenmeli ve eğitsel oyunlar oynanmalı.

\section{Sonuç ve Tartışma}

Araştırma sonucunda uzaktan eğitimle yabancı dil olarak Türkçe öğrenen Arap öğrencilerin bu süreçte en sık karşılaştıkları sorunların, "Uzaktan eğitimle ders işlerken yaşanan bağlantı problemleri", "yayın kalitesinin düşüklüğü", "evdeki fiziki imkanların sınırlı olması", "saat farkı dolayısıyla ortaya çıkan problemler", "ödevleri yalnız yapmanın zorluğu" ve "ekran karşısında uzun süre kalma" olarak sıralanabilir. Öğrencilerin önerdiği çözüm önerileri ise "uzaktan eğitim için günlük ders çalışma planı hazırlanmalıdır", "pandemide egzersizler yaparak moral ve sağlık korunmalıdır", "Türkçe kitap okumak gerekir", "derslerin tekrarı izlenmelidir", "ekran karşısında geçirilen zaman dikkat edilmelidir", "eğitsel oyunlar oynamalıdır", "Türkçe film belgesel veya animasyon izlenmelidir", " ders sorumlularıyla iletişime devam edilmesi" ve "sanal olarak Türkiye'de bulunan müze, sinema, tiyatro gezmek gerekir" şeklindedir. Karşılaşılan bu sorun ve çözüm önerilerinin bu alanda yapılan ve uzaktan eğitimde karşılaşılan problemler ve çözüm önerilerine odaklanan diğer çalışmalarda ulaşılan (Adıyaman, 2002; Brooks, vd, 2020; Cao vd., 2020; Kürtüncü ve Kurt, 2020; Lee, 2020; Owusu-Fordjour, 2020; Yamamoto ve Altun, 2020; Özbay, 2015). Sonuçlara benzer olduğu görülmektedir. Diğer bir deyişle uzaktan eğitimin kendine has imkanları ve problemlerinin yabancı dil olarak Türkçe öğretimi alanında da söz konusu olduğu söylenebilir.

Son yıllarda uzaktan eğitim olanaklarını kullanarak yapılan eğitim öğretim faaliyetlerinde bir artış olmakla beraber, COViT-19 salgını ile birlikte uzaktan eğitim yapmak bir zorunluk olarak hemen tüm eğitim ortamlarında kullanılmaya başlanmıştır. Aslında tüm dünyada uzaktan eğitime veya yüz yüze eğitimle birlikte kullanılmasına yönelik çalışmalar 1970'li yıllardan itibaren başlamıştır. Örneğin Türkiye'de MEB, 1970 yılında mektupla öğretim ile uzaktan eğitim çalışmalarına başlanmıştır. Sonrasında radyo ve televizyonun yaygınlaşması ile Açık Öğretim Lisesi ve Açık Öğretim Ortaokulu da aktif olarak faaliyete başlamıştır. 2000'li yıllardan itibaren bilgisayar ve internet teknolojilerinin yaygınlaşması ile örgün eğitime destek olmak amacıyla uzaktan eğitim çalışmalarına 2000'li yıllarda daha da hız vermiştir (Bozkurt, 2017). MEB, ayrıca uzaktan eğitime içerik sağlamak amacıyla Eğitim Bilişim Ağını (EBA) kurmuştur. Ülkelerin okullarda anadilini öğretirken uzaktan eğitimin imkanlarından yararlanması yaygınlaşırken kendi dillerini öğretmek için uzaktan eğitimin imkanlarından yararlanmaması düşünülemez. Günümüzde yabancı dil öğretiminde de uzaktan öğretimin kullanılması da giderek yaygınlaşmaktadır. Zira başka bir ülkede konuşulan dili öğrenmek için gerekli olan yazılı materyale ulaşmak oldukça kolay olmakla birlikte sözlü iletişim (konuşma ve dinleme) için de uzaktan eğitim çok çeşitli imkanlar sağlamaktadır. Bir ülkenin kendi dilini öğrenen yabancılar sayesinde sağladığı ekonomik, siyasi, bilimsel ve kültürel fayda düşünüldüğünde bu hususun kabul edilmesi kolaylaşacaktır. Bu itibarla bu araştırma sonuçlarından da hareketle yabancı dil olarak Türkçe öğretiminin uzaktan eğitimle yapılmasında dikkat edilecek hususları şu şekilde sıralamak mümkündür:

- Uzaktan eğitime, fiziksel mesafe problemini yok ettiği, aynı anda birçok kişiye ulaşım sağladığı ve ekonomik olduğu için gereken önem verilmelidir. Yabancı dil olarak Türkçe öğreten kurumlar bu sürece çok kısa sürede adapte olmalıdır.

- Yabancı dil olarak Türkçe öğreten kurumlar MEB'in uzaktan eğitim tecrübelerinden yararlanmalıdır.

- Yabancı dil olarak Türkçe öğreten eğitimciler kendilerini uzaktan eğitim konusunda da geliştirmelidir. 
- Yabancı dil olarak Türkçe öğreten eğitimciler ve ilgili kurumlar hem altyapı hem teknolojik araçları kullanma hem de uygulamalar geliştirme ve uygulama konusunda gerekli faaliyetleri yapmalıdır.

- Öğretim programı geliştirilirken ve uygulanırken hedef kitlenin yaşı, anadili, Türkçe bilgi vb. hesaba katıldığı gibi bu öğrencilerin yaşadığı ülkelerdeki saat farkı da hesaba katılmalıdır.

- Uzaktan eğitim yapılırken sürecin kendine özgü zorlukları (uzun süre ekrana bakma, hareketsiz kalma vb.) dikkate alınarak oyunlar ve fiziksel etkinliklere yer verilmelidir.

\section{Kaynaklar}

Adıyaman, Z. (2002). Uzaktan eğitim yoluyla yabancı dil öğretimi. The Turkish Online Journal of Educational Technology 1(1), 92-97.

Ağar, M. E. (2004). Türkçe öğretiminin tarihçesi. Uluslararası Insan Bilimleri Dergisi, 1, 1-10.

Akyürek, M . (2020). Uzaktan eğitim: Bir alanyazın taraması . Medeniyet Eğitim Araştırmaları Dergisi, 4(1), 1-9.

Alyılmaz, C. (2010). Türkçe öğretiminin sorunları. Turkish Studies, 5(3), 728-749.

Bakioğlu, B. ve Çevik, M. (2020). Covid-19 pandemisi sürecinde fen bilimleri öğretmenlerinin uzaktan eğitime ilişkin görüşleri. Turkish Studies, 15(4), 109-129.

Barın, E. (2003). Yabancılara Türkçenin öğretiminde temel söz varlığının önemi. TÜBAR, 13(2), 311-317.

Barın, E. (2004). Yabancılara Türkçe öğretiminde ilkeler. Türkiyat Araştırmaları, 1(1) 19-30.

Bozkurt, A. (2020). Koronavirüs (Covid-19) pandemi süreci ve pandemi sonrası dünyada eğitime yönelik değerlendirmeler: Yeni normal ve yeni eğitim paradigması. Açıöğretim Uygulamaları ve Araştırmaları Dergisi, 6(3), 112-142.

Bozkurt, A. (2017). Türkiye'de uzaktan eğitimin dünü, bugünü ve yarını. Açıköğretim Uygulamaları ve Araştırmaları Dergisi, 3(2), 85-124.

Biçer, N. (2012). Hunlardan günümüze yabancılara Türkçe öğretimi. Uluslararası Türkçe Edebiyat Kültür Eğitim Dergisi, 1(4) 107-133.

Büyüköztürk, Ş., Kılıç Çakmak, E., Akgün, Ö. E., Karadeniz, Ş. ve Demirel, F. (2008). Bilimsel araştırma yöntemleri. Ankara: Pegem Akademi Yayıncilık.

Brooks, S. K., Smith, L. E., Webster, R. K., Weston, D., Woodl, L., Hall, I., ve Rubin, G. J. (2020). The impact of unplanned school closure on children's social contact: rapid evidence review. Euro Surveilliance, 25(13).

Cao, W., Fang, Z., Hou, G., Han, M., Xu, X., Dong, J., ve Zheng, J. (2020). The psychological impact of the COVID19 epidemic on college students in China. Psychiatry Research, 287,

Clark, J. T. (2020). Distance education. (ss. 410-415). Clinical engineering handbook, ed.: ernesto iadanza. FlorinsItaly: Academic Press.

Cho M. H. ve Cho Y. (2017) Self-regulation in three types of online interaction: A scale development. Distance Education, 38(1), 70-83.

Creswell, J. W. (2011). Educational research: Planning, conducting, and evaluating quantitative and qualitative research (3. Baskı). USA: Pearson Education Inc.

Durmuş, M. (2013). Yabancılara türkçe öğretimi el kitabı. Ankara: Grafiker Yayınları.

Durmuş M. (2013). Türkçenin Yabancılara öğretimi: sorunlar, çözüm önerileri ve yabancılara Türkçe öğretiminin geleceğiyle ilgili görüşler. Adıyaman Üniversitesi Sosyal Bilimler Enstitüsü Dergisi, 6(11), 207-228.

Dikmen, S. ve Bahçeci, F. (2020). Covid-19 pandemisi sürecinde yükseköğretim kurumlarının uzaktan eğitime yönelik stratejileri: Firat Üniversitesi örneği. Turkish Journal of Educational Studies,7(2), 78-98.

Durak, G., Çankaya, S. ve İzmirli, S. (2020). Covıd-19 pandemi döneminde Türkiye'deki üniversitelerin uzaktan eğitim sistemlerinin incelenmesi. Necatibey Eğitim Fakültesi Elektronik Fen ve Matematik Eğitimi Dergisi, 14(1), 787-809.

Er, O., Biçer, N. ve Bozkırlı, K. Ç. (2012). Yabancılara Türkçe öğretiminde karşılaşılan sorunların ilgili alan yazını ışı̆̆ında değerlendirilmesi. Uluslararası Türkçe Edebiyat Kültür Eğitim Dergisi, 1(2), 51-69.

Göçer, A. ve Moğul, S. (2011). Türkçenin yabancı dil olarak öğretimi ile ilgili çalışmalara genel bir bakış. Turkish Studies, 6(3), 797-810

Güler, E. B. (2012). Yabancılara Türkçe öğretiminde "öğretmen" unsuru. International Journal of Social Science, 5(2), 129-134.

Gün M., Akkaya, A. ve Kara Ö. T. (2014). Yabancılara Türkçe öğretimi ders kitaplarının Türkçe öğretim merkezlerinde görev yapan öğretim elemanları açısından değerlendirilmesi. Turkish Studies, 9(6), 1-16.

Karababa, Z. C. C. (2009). Yabancı dil olarak Türkçenin öğretimi ve karşıllaşllan sorunlar. Ankara Üniversitesi Eğitim Bilimleri Fakültesi Dergisi, 42(2), 265-277.

Keskin, M. ve Özer Kaya, D. (2020). Covid-19 sürecinde öğrencilerin web tabanlı uzaktan eğitime yönelik geri bildirimlerinin değerlendirilmesi. İzmir Katip Çelebi Üniversitesi Sağlık Bilimleri Fakültesi Dergisi, 5(2), 59-67.

Kürtüncü, M ve Kurt, A . (2020). COVID-19 pandemisi döneminde hemşirelik öğrencilerinin uzaktan eğitim konusunda yaşadıkları sorunlar. Avrasya Sosyal ve Ekonomi Araştırmaları Dergisi, COVID-19 ÖZEL SAYISI 2, 66-77. 
Temel Eğitim Dergisi / Journal of Primary Education, 2021, 12, 18-24

Lee, J. (2020). Mental health effects of school closures during Covid-19. The Lancet Child and Adolescent Health, $395,912-20$.

Özbay, Ö. (2015). Dünyada ve Türkiye'de uzaktan eğitimin güncel durumu. Uluslararası Eğitim Bilimleri Dergisi, 2(5), 376-394.

Owusu-Fordjour, C., Koomson, C., ve Hanson, D. (2020). The impact of Covid-19 on learning- the perspective of the Ghanaian student. European Journal of Education Studies, 7(3), 88-101.

Özdemir, C. (2013) Yabancılara Türkçe öğretiminde ders malzemelerinin önemi ve işlevsel ders malzemelerinin nitelikleri. Turkish studies, 8(1), 2049-2056.

Sancak, M. ve Çöl, M. (2020). Türkiye'de COVID-19 pandemisinin kronolojik olarak incelenmesi. K. O. Memikoğlu, V. Genç (Eds.), COVID-19 (ss. 201-217). Ankara: Ankara Üniversitesi Basımevi.

Serçemeli, M. ve Kurnaz, E. (2020). Covıd-19 pandemi döneminde öğrencilerin uzaktan eğitim ve uzaktan muhasebe eğitimine yönelik bakış açıları üzerine bir araştırma. Uluslararası Sosyal Bilimler Akademik Araştırmalar Dergisi, 4(1), 40-53.

Yamamoto, G.T. ve Altun, D. (2020). Coronavirüs ve çevrimiçi (online) eğitimin önlenemeyen yükselişi. Üniversite Araştırmaları Dergisi, 3(1), 25-34. 